\title{
Human taste response as a function of locus of stimulation on the tongue and soft palate*
}

\author{
VIRGINIA B. COLLINGS $\dagger$ \\ University of Pittsburgh, Pittsburgh, Pennsylvania 15260
}

\begin{abstract}
Taste recognition thresholds and psychophysical intensity functions were determined for $\mathrm{NaCl}$, sucrose, QHCl, urea, and citric acid for four loci on the tongue and on the soft palate. The results showed greater differences between loci than previously reported. Contrary to older data, the threshold for bitter was found to be lower for the fungiform papillae at the front of the tongue and for the soft palate than for the vallate papillae. For all compounds, the slopes of the intensity functions varied with the locus of stimulation. The functions for most compounds were steepest at the vallate and foliate loci.
\end{abstract}

The presence of different patterns of threshold sensitivity across the human tongue for salty, sour, bitter, and sweet compounds is often cited in support of the concept of four "primary" qualities in taste. This evidence is based on the classic study of Hanig (1901). Hanig found the lowest threshold for bitter to be at the back of the tongue; for salty, at the front; for sweet, on the sides near the front; and for sour, on the sides near the back of the tongue. However, the maximum difference for sodium chloride and citric acid was only $0.2 \log$ unit; for quinine and sucrose, it was approximately $0.6 \log$ unit. The assumption has been that this differential sensitivity of tongue loci depends on the presence of functionally different taste receptors in each tongue area, with the population maximally sensitive to each of the four qualities being found at a different locus.

More information about coding mechanisms can be obtained by studying the response to suprathreshold concentrations. It has been reported that the exponent of the psychophysical power function relating sensation magnitude to stimulus concentration in taste has a characteristic value for each taste quality (Stevens, 1969; Moskowitz, 1970). This suggests that compounds representing a taste quality react in similar ways with the taste receptors; a compound from another taste quality would stimulate the receptor in a different way. It has been suggested that the exponent provides information about how the stimulus is bound to the receptor membrane (Smith, 1971). Differential adsorption of compounds to the receptor would be consistent with what is known about the response patterns of single taste receptor cells in the rat (Kimura \& Beidler, 1961; Ozeki \& Sato, 1972).

*This report is based on a dissertation submittcd in partial fulfillment of the requirements for the PhD degree, University of Pittsburgh. Thanks are due to Donald H. McBurney for his guidance of the author's graduate training. Part of these results were reported at the meeting of the Psychonomic Society, St. Louis, November 1972. Supported by USPHS Grant 5R 01-NB-07873 to D. H. McBurney.

tRequests for reprints should be addressed to Virginia B. Collings, 402 Langley Hall, Department of Psychology, University of Pittsburgh, Pittsburgh, Pennsylvania 15260.
If information about the rate of growth of the taste sensation were known for various loci on the tongue, it would be possible to determine how the coding of quality information varies over the receptor surface. The present studies were designed to determine the threshold and suprathreshold responsiveness of loci on the tongue and soft palate. In Experiment $I$, the threshold determinations of Hanig were partially replicated and extended, using a newer method which allows the S's threshold to be assessed independent of his criterion. The method of limits which Hanig used does not take into account possible shifts in criterion during or across experimental sessions. Recognition thresholds were determined rather than detection thresholds since the primary interest was in the coding of taste quality information. In Experiment II, the investigation was extended to suprathreshold stimuli. In both experiments, the soft palate was studied, in addition to tongue loci, in order to determine the contribution of extra-tongue loci to taste sensation.

\section{EXPERIMENT I}

\section{Method}

Subjects. Ss were students at the University of Pittsburgh who were paid for their participation in the experiment; none smoked and all were uninformed as to the purpose of the experiment.

There were three groups of Ss. Five Ss were in the citric/ $\mathrm{NaCl} /$ sucrose/quinine group on the tongue and palate, five Ss were in the citric/ $\mathrm{NaCl} / \mathrm{suc}$ rose/urea group on the tongue, and five Ss were in the citric/ $/ \mathrm{NaCl} /$ sucrose/urea group on the palate. There was a total of eight females and seven males. All Ss in Experiment I had previously participated in Experiment II. This was considered preferable to acquainting a new group of Ss with the procedure.

Solutions. Stimuli were solutions of sodium chloride, citric acid, quinine hydrochloride, urea, and sucrose in $0.1 \mathrm{log}$ molar steps, made with deionized water. Sodium chloride, citric acid, and urea were reagent grade; quinine, U.S.P.; and sucrose, commercial.

Psychophysical Method. A four-alternative forced-choice procedure was used. Different groups of Ss received urea $/ \mathrm{NaCl} /$ sucrose/citric acid or quinine/ $\mathrm{NaCl} /$ sucrose/citric, since urea and quinine are both bitter and cannot be presented in the same choice procedure. The compound presented on each trial was randomly determined, with the threshold for each being 


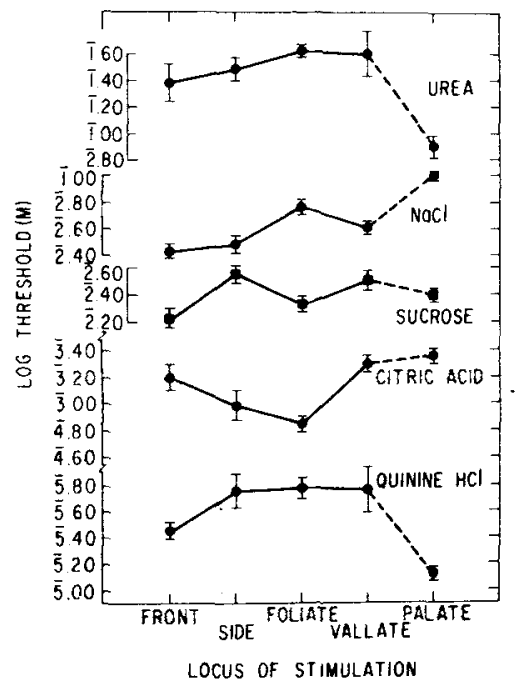

Fig. 1. Log taste thresholds for four tongue loci and the soft palate, for urea, sodium chloride, sucrose, citric acid, and quinine hydrochloride. The horizontal lines indicate $\pm l$ standard error of the mean.

determined by a tracking procedure (Cornsweet, 1962). The four compounds were tracked simultaneously, with the concentration of the stimulus being increased or decreased by $0.1 \log$ step, depending on that S's response on the last presentation of that stimulus. After the initial reversal, the mean (geometric) of the molar concentrations where the next six reversals occurred was taken as the measure of the threshold for each stimulus and locus; if six reversals were obtained for one stimulus before completing the tracking for the other three, the tracking was continued for that stimulus, with the mean of the six reversals af ter the first being used. In signal detection terminology, the stimulus presented on a given trial is the signal, while the three qualities not presented are noise $\left(\mathrm{d}^{\prime}=0.81\right)$. A preliminary test was used to determine the starting concentrations for the first $S$; after that time, each $S$ was started at the concentration where the previous S's last reversal on that compound had occurred.

Procedure. The $\mathrm{S}$ first rinsed his mouth with distilled water, and then extended his tongue for the presentation of the stimulus. The stimulator was a round piece of filter paper, $4.0 \mathrm{~mm}$ in diam, which was dipped into a solution, the excess drained off by touching the side of the cup, and placed on the S's tongue or palate with small forceps. Five loci on the left side of the tongue were studied. The locus at the tip of the tongue stimulated 9-10 fungiform pipillae, and one $2.5 \mathrm{~cm}$ back on the side, 7-8 fungiform papillae. One foliate or 1 vallate papilla was stimulated at the other tongue loci. The soft palate locus was slightly to the left of the uvula.

After placement of the stimulus, the $S$ kept his tongue extended until he made his response by pointing to a card bearing the name of the taste quality-salty, sour, sweet, or bitter. He then rinsed his mouth twice with distilled water. The E gave the $S$ feed back after each trial. A record was kept by the $E$ of the nature of all incorrect responses. The intertrial interval was $20 \mathrm{sec}$. An experimental session consisted of the completion of the four-alternative procedure for two loci. The four threshold determinations at a given locus were completed before proceeding to the next locus, with the loci being studied in a different order for each $\mathrm{S}$.

The filter paper procedure, used by Hara (1955) allows the discrete localization of the stimulus and makes it possible to check placement during the stimulation process. A test with food coloring proved the spread to be minimal. Other procedures, such as the fine brush used by Hanig (1901) or needle syringe (von Békésy, 1966), do not control spread and provide no way to check locus of stimulation after initial placement. Other methods which may give better control over area of stimulation include the ring stimulator used by Harper, Jay, \& Erickson (1966), a glass tube with an opening placed on the tongue (Bujas \& Ostojcic, 1941), and a block stimulator with slits for flow designed by von Békésy (1964). The disadvantage of such stimulators is that they cannot be used to stimulate the foliate and vallate papillae at the back of the tongue because of their size and the difficulty of placement.

\section{Results}

The mean thresholds obtained are represented logarithmically in Fig. 1, with the standard error of the mean for each point given to indicate inter-S variability. For sodium chloride, the lowest thresholds were found at the fungiform papillae, and the highest on the soft palate. The lowest threshold for citric acid was at the foliate papillae; the highest was on the palate. The maximum difference for both sodium chloride and citric acid is about $3: 1$. For sucrose, the threshold was lowest on the front of the tongue, and highest on the side. The lowest threshold for both urea and quinine was on the soft palate; also, for both compounds, the lowest tongue threshold was at the front of the tongue.

In this procedure, the probability of getting the quality correct by chance is $25 \%$; by using the tracking procedure, the $50 \%$ correct level is taken as the measure of the S's threshold for each compound. This is valid if the Ss do not show a response bias for quality at any locus. The data were analyzed for such biases. With a chi-square analysis, the observed response frequencies were tested against an expected distribution with equal probabilities of responding in each of the four quality categories for each locus. All of the resulting chi-square values for individual Ss were nonsignificant $(\mathrm{p}<10, \mathrm{df}=$ 12 ), indicating that there were no response biases on the part of the Ss.

\section{EXPERIMENT II}

\section{Method}

Preliminary Study. Twenty Ss made magnitude estimates of four concentrations $(0.5 \log$ unit apart) each of six stimuli (urea, sodium chloride, magnesium sulfate, quinine hydrochloride, sucrose, and citric acid) presented to the four loci on the tongue using the filter paper procedure. The data showed a great deal of variability, indicating that the task was too difficult. Therefore, a matching procedure was used.

Subjects. The Ss were students at the University of Pittsburgh, 15 females and 13 males, naive as to the purpose of the study and nonsmokers. They were paid for their participation. There were $7 \mathrm{Ss}$ in each of the following groups: front, side, foliate, and vallate loci with citric acid and sucrose; the same loci with quinine, urea, and sodium chloride; front, vallate, and palate loci with citric and sucrose; and the same loci with quinine, urea, and sodium chloride. The $\mathrm{S}$ groups as described were a result of the length of time necessary to complete the experiment and the problems involved in using a changing student population as the source of Ss.

Solutions. Comparison stimuli were solutions of sodium chloride, citric acid, urea, quinine hydrochloride, and sucrose in $0.1 \log$ molar steps, as in Experiment I. Standard stimuli were solutions of sodium chloride, $0.5 \log$ step apart: $0.1,0.32,1.0$, 
and 3.2 molar. The number of standards used with each comparison stimulus was determined by the solubility range of the comparison stimulus.

Psychophysical Method. The concentration of each of the comparison stimuli which, for each of the five loci, tasted equivalent in intensity (irrespective of quality) to each of the standard solutions was determined by using a tracking procedure. The concentration of the comparison stimulus was increased by $0.1 \mathrm{log}$ step if it tasted less intense than the standard, or decreased by the same amount if it tasted more intense than the standard. The tracking was continued for seven reversals, with the mean (geometric) of the concentrations at the last six reversals taken as the matching concentration. The

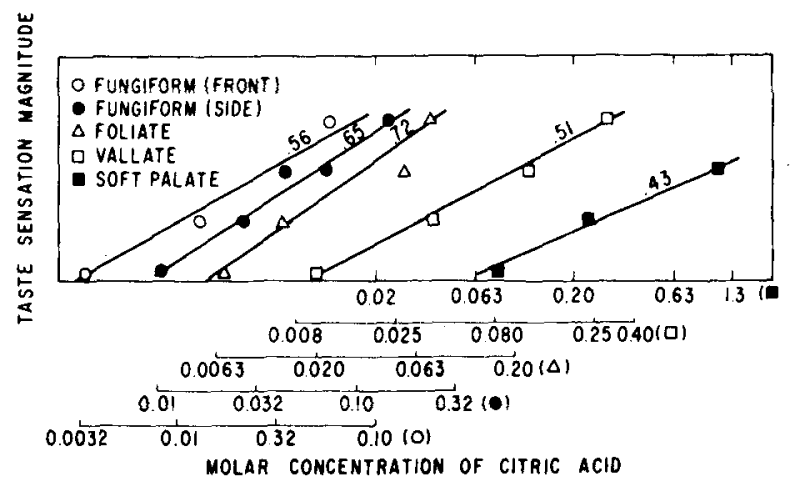

Fig. 2. Taste sensation magnitude as a function of the molar concentration of citric acid for the loci stimulated. Each slope is shown above the appropriate line. The abscissa for each function is indicated by its symbol.

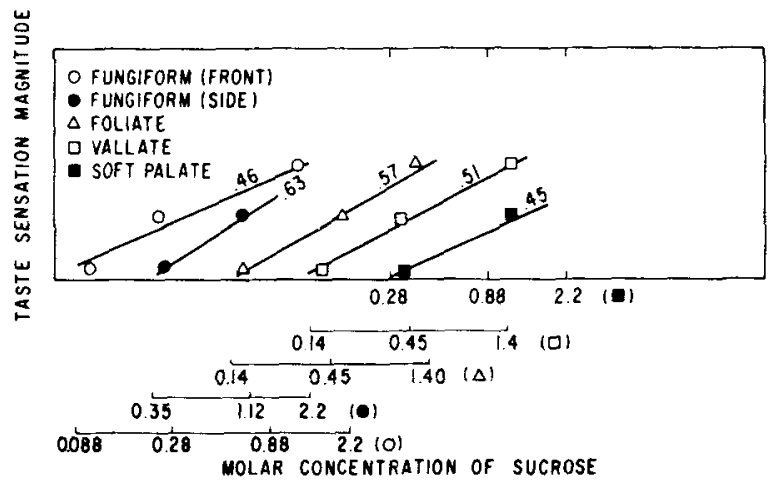

Fig. 3. Same as Fig. 2, for sucrose.

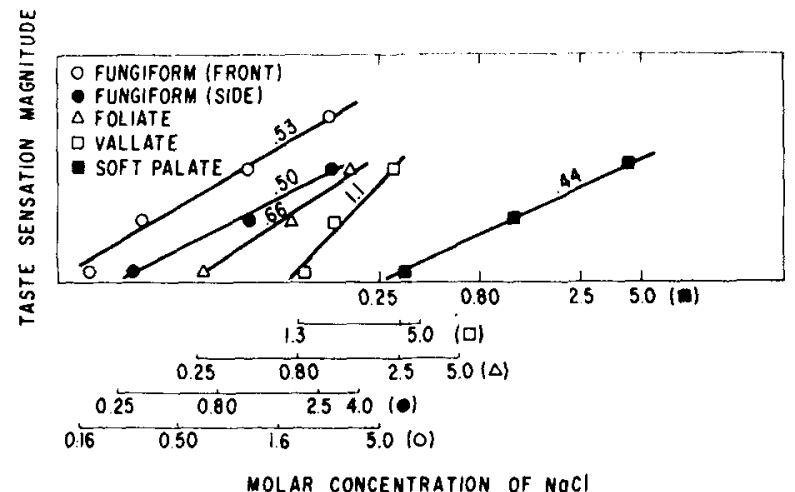

Fig. 4. Same as Fig. 2, for sodium chloride.

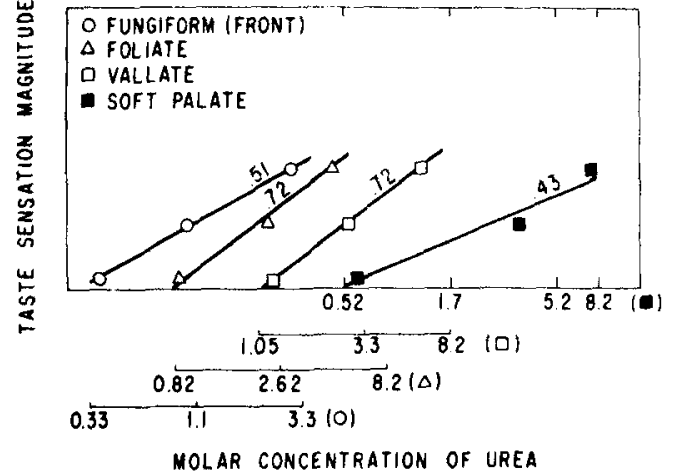

Fig. 5. Same as Fig. 2, for urea.

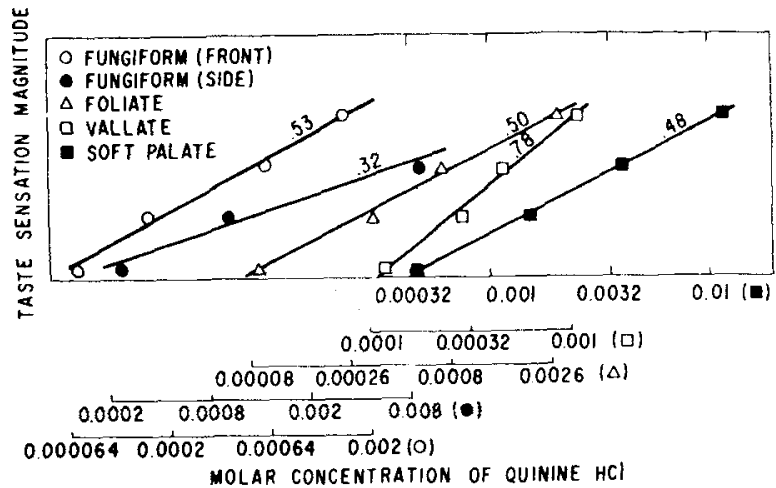

Fig. 6. Same as Fig. 2, for quinine hydrochloride.

starting concentration for the first $S$ was determined in preliminary trials, and each subsequent $S$ was started at the concentration on which the last $S$ on that determination had his last reversal. Each $S$ was run in a different order, both of loci and standards.

Procedure. Stimulation was accomplished by means of small pieces of filter paper, as described in Experiment $I$, dipped into the appropriate solutions, and placed on the tongue or palate with a pair of forceps. Two stimuli were presented simultaneously: the standard to the right side of the front of the tongue and the comparison stimulus to any of the four loci on the left side of the tongue or to the locus on the soft palate. After $5 \mathrm{sec}$, the $S$ indicated verbally which of the stimuli tasted stronger, or had a more intense taste, without paying any attention to the quality of either stimulus. He then rinsed the stimuli off his tongue with distilled water. The intertrial interval was $20 \mathrm{sec}$. One experimental session consisted of the completion of six tracking procedures, each composed of seven reversals.

\section{Results}

The sodium chloride function for the front of the tongue was assigned a slope of 0.5 . This slope is approximately that reported for sodium chloride on the front of the tongue (McBurney, 1966). All other functions, obtained by matching to sodium chloride standards on the front of the tongue, were transformed into psychophysical intensity functions based on this sodium chloride slope. Functions fitted by the least squares method are shown in Figs. 2-6.

This experiment had a split-split-plot design with 
Table 1

Analysis of Variance: Experiment II

\begin{tabular}{lrrrrc}
\hline & \multicolumn{1}{c}{$\begin{array}{c}\text { Mean } \\
\text { Source of Variation }\end{array}$} & Square & df & F & p \\
\hline Compound Groups & A & 3.293 & 1 & 7.377 & $<.01$ \\
Loci & B/A & 4.131 & 4 & 9.262 & $<.01$ \\
A by B/A,B & 3.229 & 4 & 7.230 & $<.01$ \\
Error: Residual/A,B,AB & 0.446 & 24 & & \\
\hline
\end{tabular}

incomplete repeated measures (Kirk, 1969). The analysis of variance used the slope for each group of seven Ss because of the incomplete repeated measures and one missing cell (no slope could be determined at the side of the tongue for urea due to its limited solubility). This analysis is summarized in Table 1 . The $A$ factor has two levels: A1 is quinine, urea, and sodium chloride, and A2 includes citric acid and sucrose. The reason for these two levels is that the initial interest was in the bitter taste quality, and therefore urea and quinine were used with the first group of Ss; sodium chloride was also included, since it was being used as the standard stimulus. Other groups were subsequently added on citric acid and sucrose in order to investigate the sour and sweet qualities as well. $\mathrm{B}$ is the locus of stimulation with five levels; C, the five compounds; and S, Ss with four groups. As shown in Table 1, the effect of locus (B) and the effect of compound group (A) were significant at $p<.01$; the interaction of A by B was also significant at $\mathrm{p}<.01$. All other effects were nonsignificant.

Multiple comparisons $(p<.05)$ were made with Duncan's multiple range test, using the slopes for all loci and compounds. These comparisons are shown in Table 2.

For citric acid, the steepest slopes were at the side and foliate; the foliate slope was significantly different from those at the back of the tongue and palate. For sucrose, the slopes did not differ significantly. The vallate papilla slope was significantly steeper than all other loci for sodium chloride. There was a large difference in slopes for sodium chloride, on the order of 2:1. Both urea and quinine showed the steepest slopes at the vallate papillae, although for urea the back was not significantly steeper than the foliate. For urea, only one point could be determined at the side of the tongue, and therefore no function is shown.

All slopes on the palate were between .43 and .48 , and did not differ significantly. Similarly, on the front of the tongue, the slopes were not significantly different. On the side and on the vallate, citric and sucrose did not differ significantly from each other, but the two compounds did differ from bitter (urea and quinine) and salt. The foliate was the only locus where quinine and urea differed significantly; here, sucrose and quinine had similar slopes.

\section{DISCUSSION}

The threshold data differed in several ways from the data of Hanig (1901). Greater differences were found between loci for sodium chloride and citric acid than were reported in the earlier study. The greatest difference between these data and Hanig's was for the bitter quality. Hanig reported decreasing thresholds from the front to the back of the tongue; in this study, the lowest tongue threshold was found at the fungiform papillae on the front of the tongue. However, the thresholds for both urea and quinine were lower on the soft palate than on any tongue locus, similar to the findings of Henkin \& Christiansen (1967). Hanig used a brush to present the stimulus, and since the soft palate and the vallate papillae are very close together, inadvertent stimulation of the soft palate may account for the difference in results.

Urea was included in these studies for the purpose of comparing it with quinine, since both are bitter stimuli. There is some evidence from cross-adaptation studies (McBurney, Smith, \& Shick, 1972) that the two chemicals do not affect the same receptor system since urea cross-adapts quinine and other bitter substances, but quinine does not cross-adapt urea. However, there is no evidence from either the pattern of threshold or suprathreshold data to indicate any difference between the two compounds. The slopes for the two compounds for the front and the back of the tongue and for the palate were not significantly different; the only difference between the two compounds was on the foliate papillae, where urea had a steeper slope than quinine. Urea has a sour component which is not present with quinine. The foliate papillae are very responsive to sour; therefore, the steeper foliate slope for urea may be due to its sour component.

For both urea and quinine, the vallate papillae had significantly steeper slopes than the fungiform papillae on the front of the tongue. Thus, although the

Table 2

Multiple Comparisons Among Slopes by Locus and Compound Based on Duncan's Multiple Range Test

\begin{tabular}{|c|c|c|c|c|c|}
\hline $\begin{array}{l}\text { Locus } \\
\text { Front }\end{array}$ & Sucrose & Urea & $\mathrm{QHCl}$ & $\mathrm{NaCl}$ & Citric \\
\hline Side & $\mathrm{QHCl}$ & $\mathrm{NaCl}$ & Sucrose & Citric & \\
\hline Foliate & $\mathrm{QHCl}$ & Sucrose & $\mathrm{NaCl}$ & Citric & Urea \\
\hline Vallate & Citric & Sucrose & Urea & $\mathrm{QHCl}$ & $\mathrm{NaCl}$ \\
\hline Palate & Urea & Citric & $\mathrm{NaCl}$ & Sucrose & $\mathrm{QHCl}$ \\
\hline $\begin{array}{c}\text { Compound } \\
\mathrm{NaCl}\end{array}$ & Palate & Side & Front & Foliate & Vallate \\
\hline Urea & Palate & Front & Foliate & Vallate & \\
\hline $\mathrm{QHCl}$ & Side & Palate & Foliate & Front & Vallate \\
\hline Sucrose & Palate & Front & Vallate & Foliate & Side \\
\hline Citric & Palate & Vallate & Front & Side & Foliate \\
\hline
\end{tabular}

Note-Any two loci or compounds not underscored by the same line are significantly different $(p<.05)$. 
fungiform have a lower threshold for bitter, at moderate concentrations for quinine $(>0.0005$ molar) and high concentration for urea $(>8.0$ molar $)$, the vallate are more responsive to bitter than the fungiform. This greater responsiveness of the vallate papillae to bitter combines with the low bitter thresholds of the palate to give the subjective observation of a strong bitter taste at the back of the mouth.

With both urea and quinine, the sensitivity (reciprocal of threshold) was negatively correlated with slope (Pearson $r=-0.15$ for quinine; $r=-0.85$ for urea). A high negative correlation was also found with sucrose ( $\mathrm{r}$ $=-0.74)$. However, no correlation was found for sodium chloride, and citric acid had a high positive correlation ( $\mathrm{r}$ $=0.96$ ). Thus, there does not appear to be a constant relationship between threshold sensitivity and the growth of the suprathreshold sensation.

The contribution of extratongue loci has not been taken into consideration in most taste research. It has been shown that the newborn has a large number of taste buds on the soft palate (Lalonde \& Eglitis, 1961); Braus (1940) showed histologically that taste buds are present on the soft palate of the human adult. Preliminary observations in this study indicated that thresholds for the compounds used could not be determined for the hard palate. However, the soft palate was sensitive to all five compounds. For urea and quinine, the palate was more sensitive than any tongue area. Similar observations had previously been reported by Henkin \& Christiansen (1967) using a procedure eliminating other mouth areas by anesthetization. All compounds used in the present studies showed similar slopes for the growth of sensation on the soft palate. However, for most compounds, this slope was different from that on tongue loci. This suggests that if the palate plays a role in quality coding, it may be based on its differential threshold sensitivity or it may function as part of a pattern from different parts of the mouth.

The differences in threshold for each taste quality on different loci could be due either to a differential distribution of receptors responding to the various taste qualities or to differential binding of certain taste substances by the receptors. If the differences in threshold for a given taste quality are due only to a variation in the number of receptors present at each locus, it would be expected that each locus would have a different threshold for that quality, but parallel intensity functions, since Smith (1971) has shown that varying the number of receptors stimulated at the front of the tongue does not change the slope of the psychophysical function for a given taste compound. Smith also found that the differential area effect on the threshold for different compounds was not the result of a differential distribution of sensitivities to compounds on the front of the tongue, but was due to unequal binding strengths for different taste stimuli. In support of this concept of selective adsorption, electrophysiological findings indicate that a taste cell in the rat is nonspecific in its response to taste stimuli, but it may give a greater response to representatives of one quality (Ozeki \& Sato, 1972). The significant effect of locus in the present study would be consistent with a differential distribution on the tongue and palate of broadly tuned, yet differentially responsive, receptor cells; it implies that a stimulus is selectively bound by taste receptors as a function of locus on tongue or palate. The effect of locus is a reflection of the characteristics of the particular receptor population present in each locus.

It has been generally accepted that the slope of the psychophysical function is an indicator of the taste coding mechanism, since each taste quality appears to be governed by a different exponent (Stevens, 1969; Moskowitz, 1971). However, such functions are usually obtained by stimulating either the front third of the tongue or the whole mouth. Differences in slope have been reported from different presentation procedures used in taste experiments (Meiselman, 1971). The sip procedure and those flow procedures that stimulate the whole mouth yield higher exponents than the dorsal tongue flow procedures which stimulate only the front third of the tongue. In the present study, for sodium chloride, urea, and quinine, the steepest slope was at the back of the tongue; for citric acid and sucrose, the foliate was steeper than the front. Thus, it appears that differences in exponent reported by these studies using different presentation procedures may be in part explained by their stimulation of different tongue loci which have different rates of growth of the taste sensation.

The significant effect of locus also suggests that the growth of the taste sensation for a given quality is not a function simply of the type of papilla stimulated or of the particular nerve involved. For quinine, the slope for the front of the tongue was significantly different from that for the side, although both loci contain fungiform papillae and are innervated by the chorda tympani nerve. The slope at the vallate papillae was significantly different from the slope at the foliate papillae for sodium chloride, quinine, and citric acid. Both the vallate and the foliate papillae are innervated by the glossopharyngeal nerve.

The Compound Group by Locus interaction was significant; this indicates that each compound group (quinine-urea-sodium chloride; sucrose-citric) had a different pattern of slopes across the five loci. As shown in Table 2, within the first group, urea and quinine differed in slope only at the foliate papillae. Sodium chloride slopes were significantly different from those for urea and quinine at the vallate and foliate loci. In the second group, citric and sucrose differed in slope at the foliate locus. Citric acid is often reported to have a sweet component as well as sour; this may partly account for its similarity to sucrose. Although each compound group had the same pattern of slopes across the loci, the compounds, with the exception of urea and quinine, differed in the steepness of slope at several loci. 
The data from these studies imply that the two bitter compounds tested, urea and quinine, are coded by a common mechanism, since their patterns of threshold and suprathreshold response are similar across the locations studied. Each of the other qualities had different patterns of threshold and growth of suprathreshold sensation across the five loci. These findings support the concept of "primary" taste qualities with different coding mechanisms.

\section{REFERENCES}

Braus, H. Anatomie des Menschen. Band IV. Berlin: Julius Springer, 1940. Cited by Marcström, A. Studies on the connection between physicochemical properties and stimulating abilities of some sweet and bitter compounds. Arkiv för Zoologi, 1967, 19, 422 .

Bujas, Z., \& Ostojcic, A. La sensibilitê gustative en fonction de la surface excitee. Acta Instituti Psychologici Universitatis Zagrebensis, 1941, 13, 1-19.

Cornsweet, T. N. The staircase method in psychophysics. American Journal of Psychology, 1962, 75, 485-491.

$H$ anig, D. P. Zur Psychophysik des Geschmacksinnes. Philosophische Studien, 1901, 17, 576-623.

$H$ ara, S. Interrelationship among stimulus intensity, stimulated area and reaction time in the human gustatory sensation. Bulletin of the Tokyo Medical \& Dental University, 1955, 2, 147-158.

Harper, H. W., Jay, R., \& Erickson, R. P. Chemically evoked sensations from single human taste papillae. Physiology \& Behavior, 1966, 1, 319-325.

Henkin, R. I., \& Christiansen, R. L. Taste localization on the tongue, palate, and pharynx of normal man. Journal of Applied Physiology, 1967, 22, 16-320.
Kimura, K., \& Beidler, L. M. Microelectrode study of taste receptors of rat and hamster. J ournal of Cellular \& Comparative Physiology, 1961, 58, 131-139.

Kirk, R. E. Experimental design: Procedures for the behavioral sciences. Belmont, California: Brooks/Cole, 1969.

Lalonde, E. R., \& Eglitis, J. A. Number and distribution of taste buds on the epiglottis, larynx, soft palate, and uvula in a human newborn. Anatomical Record, 1961, 140, 91-95.

McBurney, D. H. Magnitude estimation of the taste of sodium chloride after adaptation to sodium chloride, Journal of Experim ental Psychology, 1966, 72, 869-873.

McBurney, D. H., Smith, D. V., \& Shick, T. R. Gustatory cross adaptation: Sourness and bitterness. Perception \& Psychophy sics, 1972, 11, 228-232.

Meiselman, H. L. Effect of presentation procedure on taste intensity functions. Perception \& Psychophysics, 1971, 10. 15-18.

Moskowitz, H. R. Ratio scales of sugar sweetness. Perception \& Psychophysics, 1970, 7, 315-320.

Moskowitz, H. R. Intensity scales for pure tastes and for taste $\mathrm{m}$ ix tures. Perception \& Psychophy sics, 1971, 9, 51-55.

Ozeki, M., \& Sato, M. Responses of gustatory cells in the tongue of rat to stimuli representing four taste qualities. Comparative Biochem istry \& Phy siology, 1972, 41, 371-407.

Smith, D. V. Taste intensity as a function of area and concentration: Differentiation between compounds. Journal of Experimental Psychology, 1971, 87, 163-171.

Stevens, S. S. Sensory scales of taste intensity. Perception \& Psychophysics, 1969, 6, 302-308.

von Békésy, G. Rhythmical variations accompanying gustatory stimulation observed by means of localization phenomena. Journal of General Physiology, 1964, 47, 809-825.

von Békésy, G. Taste theories and the chemical stimulation of single papilla. Journal of Applied Physiology, 1966, 21, 1-9.

(Received for publication October 22, 1973; accepted March 19, 1974.) 